Bernal Rivas, Gonzalo Enrique.

Profesor de tiempo completo, Universidad de Guanajuato, ENMS de Salamanca, área de artes.

\title{
Carnet de soltero/a: un proyecto artístico guanajuatense con referentes globales.
}

\section{Single license: an artistic project made in Guanajuato with a global background.}

\author{
TIPO DE TRABAJO: \\ Comunicación. \\ PALABRAS CLAVE: \\ Experiencia, espacio, global, carnet, estado civil.
}

KEY WORDS:

Experience, space, global, license, marital status.

\section{RESUMEN.}

Carnet de soltero/a es una obra de arte de la experiencia del espacio humano que consiste en la emisión de carnets que avalan a sus poseedores/as como discapacitados/as, un resultado virtual del artículo de Henry Bodkin publicado en The telegraph el 20 de octubre de 2016, según el cual la OMS definiría como "infértiles" a las personas solteras, y por lo tanto, de acuerdo al glosario de la misma organización, como "discapacitadas". Lo anterior para favorecer una reflexión entre los participantes sobre las vivencias de injusticia espacial vinculadas con el estado civil que un hecho como el descrito generaría.

En esta comunicación no pretendemos demostrar que muchas de las actividades que realizamos en nuestros entornos locales se encuentran cada vez con mayor frecuencia bajo la influencia de los sucesos globales o viceversa, pero sí deseamos compartir el proceso creativo de Carnet de soltero/a, el cual partió de un supuesto acontecimiento local que podría tener efectos globales: la decisión tomada por un grupo reducido de personas reunidas en Ginebra sobre todo el mundo. Más allá de ese punto de partida, los referentes empleados también tienen orígenes diferentes al contexto guanajuatense, México, Estados Unidos y España. El primer referente es Minerva Cuevas (1998) con su pieza Mejor Vida Corp. en la cual se ofrecieron ayudas a los ciudadanos, como carnets de estudiante o cartas de recomendación, y que tenía como objetivo mostrar al gobierno los apoyos que los ciudadanos requerían prioritariamente. Por otra parte revisamos Wedding Project de Alix Lambert (1993) en la que se abordó la fugacidad con la que era posible de los años 90 cambiar de estado civil. Finalmente nos referimos a David Trullo (2010) con su obra Una historia verdadera en la que muestra las relaciones entre personas del mismo género que nunca fueron representadas.

\section{ABSTRACT.}

Carnet de soltero/a is a piece of art of the human space experience that consists in issuing licenses that endorse their owners as disabled, a virtual result of Henry Bodkin's article published in The telegraph on October $20^{\text {th }}, 2016$, according to which the WHO would define single people as "infertile", and therefore, in agreement to that same organization, as "handicapped". The above to stimulate a reflection among the participants about the experiences of spatial injustice related to the marital status that a fact as the one described would generate. 
In this talk we don't pretend to demonstrate that many of the activities that we do in our local environments are at each time more frequently under the influence of the global evets or viceversa, but we wish to share the creative process of Carnet de soltero/a, which began at a supposed local fact that could have global effects: the decision made by a small group of people gathered in Geneva over the whole world. Beyond this departing point the consulted background also have different origins to the context of Guanajuato, Mexico, the United States and Spain. The first precedent is Minerva Cuevas (1998) with her piece Mejor vida Corp.in which help was offered to the citizens, such as student licenses or recommendation letters, and that had as an objective to show the government the priority support that the citizens required. Moreover, we reviewed Wedding Project by Alix Lambert (1993) where the fugacity at which it was possible to change one's marital status during the 90s was addressed. Finally, we refer to David Trullo (2010) with his piece Una historia verdadera in which he shows same-gender relationships that were never represented.

\section{CONTENIDO.}

\section{Introducción}

El desarrollo de esta comunicación está estructurado en cuatro secciones. En la primera se define un concepto teórico fundamental para la realización de la pieza, el arte de la experiencia del espacio humano, destacando una propuesta de tipología basada en el vínculo entre el deterioro de las relaciones humanas y el empobrecimiento del espacio humano. También se menciona el término justicia espacial de Edward Soya (2010) y se muestran algunas reflexiones que podría favorecer la pieza. En el siguiente apartado se incluyen los hechos históricos que condujeron a la concepción de la pieza. En la tercera parte, se muestran tres referentes artísticos, procedentes de latitudes diferentes, Mejor Vida Corp. de la mexicana Minerva Cuevas (1998), Wedding Project de la estadounidense Alix Lambert (1993) y Una historia verdadera del español David Trullo (2010). Adicionalmente se incluyó The proposal de la estadounidense Jill Magid (2016). Finalmente, se describe Carnet de soltero/a, se muestran cuatro de las identificaciones y la ficha técnica, y se mencionan los recursos materiales y retos que supuso la ejecución de la pieza.

\section{Desarrollo.}

Antes de abordar el tema central de esta comunicación es importante mencionar brevemente que en la tesis doctoral "Cuestionamiento y recuperación de la experiencia del espacio humano en el arte mexicano contemporáneo (1997-2014)." se propuso un término fundamental para concebir y ejecutar Carnet de soltero/a, nos referimos al arte de la experiencia del espacio humano, el cual se define como un conjunto de prácticas artísticas cuyo tema central o materia de creación es la experiencia del espacio integrado por la combinación del arquitectónico y del urbano en el sentido propuesto por María Isabel Ramírez ${ }^{1}$. Se encontró además que existe un vínculo entre el deterioro de las relaciones humanas y el empobrecimiento del espacio humano, y en base a esto se planteó una tipología de obras de arte de la experiencia del espacio humano, la cual, sin intención de ser exhaustiva, nos permitió definir cinco líneas de acción de la forma de arte señalada. Dicha clasificación depende de la relación entre determinadas formas de empobrecimiento de la vivencia y ciertos daños de las relaciones humanas (la falta de identidad, la manipulación, la invisibilidad, la fugacidad y el uso irreflexivo de la tecnología).

Recientemente, y derivado en parte de nuestro interés en la idea de justicia espacial de Edward Soja, la cual se define como "...lo que surge de la aplicación de una visión espacial crítica a lo que se conoce comúnmente como justicia social." ${ }^{2}$, hemos creado la pieza que presentamos en esta ocasión y en la que se examinan las consecuencias potenciales si los/las solteros/as fueran calificados como discapacitados, como tener un carnet que los acredite como discapacitados, tener placas para estacionarse en lugares reservados para discapacitados, hacer uso de las filas preferentes, ocupar asientos reservados para discapacitados en teatros, obtener descuentos en el transporte público, entre otros. Así, se concibió una pieza que aunque no pertenece a ninguna de las categorías de la tipología mencionada, o que corresponde a varias de ellas, sí trata particularmente sobre las experiencias de injusticia espacial relacionadas con el estado civil, al analizar el nexo que podría existir entre la distinción por pertenecer a un determinado sector de la población y las vivencias del espacio que compartimos.

Una vez expuestos los antecedentes teóricos de nuestra pieza, es esencial resaltar los acontecimientos históricos que detonaron su creación. El 20 de octubre de 2016, Henry Bodkin, un periodista del diario inglés The Telegraph, publicó el artículo Single men will get the right to start a family under new definition of infertility. En él declaró que "La Organización Mundial de la Salud está por anunciar que los hombres y mujeres solteros sin problemas médicos serán clasificados como «infértiles» si no tienen hijos pero quieren

\footnotetext{
${ }^{1}$ RAMÍREZ, María Isabel. El espacio urbano y arquitectónico como espacio del hombre. La conquista del lugar. Thémata, no. 11, 1993, $126-133$.

${ }^{2}$ SOJA, Edward W. En busca de la justicia espacial. Valencia: Tirant humanidades, 2014, p.38.
} 
convertirse en padres" ${ }^{3}$ Esta publicación generó un escándalo internacional que fue ampliado por otros medios de comunicación y obligó a que la OMS emitiera un comunicado al día siguiente, en el que se dio a conocer que la "La OMS está colaborando actualmente con sus compañeros para actualizar el Glosario y se está considerando revisar la definición de infertilidad. De haber un cambio en la definición de infertilidad, esta se mantendrá como una descripción clínica de infertilidad como una enfermedad del sistema reproductivo y no se harán recomendaciones sobre disposiciones de los servicios de cuidado de la fertilidad." ${ }^{\prime 4}$ Estos hechos nos llevaron a repensar, en primera instancia, el papel actual de los medios. Por otra parte, ¿quiénes integran la OMS? "Más 7000 personas de más de 150 países trabajan para la Organización en 150 oficinas de país, zonas o territorios, seis oficinas regionales y la Sede, que se encuentra en Ginebra, Suiza." ${ }^{5}$ Pero la actualización de la definición de soltero/a no está a cargo de todas ellas, sino de una comisión integrada por solamente seis personas que son miembros ejecutivos de cuatro ONGs: Fernando Zegers-Hochschild, Sheryl van der Poel, David Adamson, Joe Leigh Simpson, Gamal I Serour y Richard Reindollar. ${ }^{6}$ Por supuesto, se trata de expertos en materia de infertilidad y subfertilidad, pero si consideramos que las decisiones que toma este reducido grupo de personas afecta al mundo entero podemos dimensionar, los efectos globales que un acontecimiento local, como una reunión en Ginebra, puede alcanzar. A partir de esta información es que planteamos Carnet de soltero/a, que paradójicamente, tiene referentes de tres países diferentes, México, Estados Unidos y España, lo cual agrega una reflexión adicional que tiene que ver con el proceso creativo. Ser un artista local actualmente tiene implicaciones mundiales. Desde nuestra formación estamos expuestos a la influencia del trabajo de creadores procedentes de todas partes del globo, no solo porque disponemos de una cantidad exagerada de información con los orígenes más diversos gracias a internet, sino por los intercambios internacionales y los eventos académicos organizados en países diferentes al nuestro. Por supuesto estos hechos nos nutren, nos dan a conocer más antecedentes y nos permiten saber más en poco tiempo, pero también existen consecuencias negativas. Debemos ser más creativos porque la competencia a la que nos enfrentamos es global y la cantidad de ideas es enorme, sin mencionar la marca ecológica que nuestras acciones, tales como los vuelos internacionales o la generación de basura electrónica.

Centrándonos ahora en los precedentes artísticos de la pieza que desarrollamos nos referiremos primero a Mejor vida Corp. (MVC) de la artista mexicana Minerva Cuevas. La idea nació mientras Cuevas viajaba en metro y vio un anuncio que sugería al usuario no quedarse dormido por seguridad, motivo por el cual la artista regresó al día siguiente a repartir pastillas de café entre los usuarios de este medio de transporte. El proyecto inició en 1998 y contradice las relaciones comerciales a través de la ejecución de algunas acciones propuestas o registradas en un sitio web. La página web (http://www.irational.org/mvc/espanol.html) sigue disponible y el menú está organizado en productos, servicios, envíos, campañas, M.V.C., oficinas y contacto. Algunos de los productos que se ofrecen son boletos para el metro (que se ofrecen en la fila de la taquilla), sobre con timbre postal incluido (que se dejan periódicamente en lugares públicos), semillas mágicas que se distribuyeron en cajeros automáticos en la ciudad de México, credenciales de estudiante (los datos pueden llenarse en el sitio web), boletos de lotería (que se regalan en espacios públicos) y gas lacrimógeno. Algunos de los servicios son una encuesta sobre violencia, servicio de limpieza STC (Secretaría de Transportes y Comunicaciones), cartas de recomendación (colaboraron con el proyecto The Lisson Gallery de Londres y La Galerie Chantal Crousel de París), donaciones públicas (para apoyar a la organización) y servicio de seguridad en el que se denuncia que una representante de MVC no fue admitida en la convocatoria para trabajar como Policía Federal Preventiva por ser mujer. En la sección de campañas se denuncian injusticias como el hecho de que los indigentes no son incluidos en el censo nacional de población realizado por el INEGI (Instituto Nacional de Estadística y Geografía); también se pone en duda que la lotería nacional use los fondos de las ventas para la asistencia pública y se da la opción a de apoyar distribuyendo carteles, donando dinero o donando en especie para imprimir carteles que denuncian esto; y se documenta una manifestación en la que un grupo de personas se presentaron con carteles (con consignas como banco mundial = mafia criminal o pueblo endeudado = país controlado) frente al Banco Mundial y a la Bolsa Mexicana de Valores. En la sección MVC se presentan dos artículos y una conversación con Hans Ulrich. Lo anterior para hacer visible frente a las instituciones y al gobierno los apoyos que los ciudadanos requieren y puedan tener una percepción completa de esto.

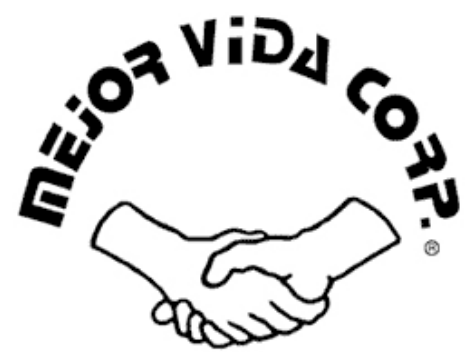

\section{Par una interfase humana \\ Ilustración 1. Logotipo de Mejor Vida Corp.}

\footnotetext{
${ }^{3}$ http://www.telegraph.co.uk/news/2016/10/19/single-men-will-get-the-right-to-start-a-family-under-new-defini/

${ }_{5}^{4} \mathrm{http}: / / \mathrm{www}$. who.int/reproductivehealth/topics/infertility/multiple-definitions/en/

${ }^{5} \mathrm{http}: / /$ www.who.int/about/structure/es/

${ }^{6} \mathrm{http} / / / \mathrm{www}$.who.int/reproductivehealth/topics/infertility/new/en/
} 
Un segundo referente es Wedding Project de la artista estadounidense Alix Lambert (1993). La pieza consistió en que la artista se casó y se divorció de tres hombres y una mujer en seis meses. Guardó los objetos generados por estas acciones, tales como actas de matrimonio y divorcio, fotografías, regalos de bodas y películas, y los expuso. Esta obra resultó de interés para Carnet de soltero/a porque en ella se aborda la diferencia entre lo que se establece en un contrato y la relación real. Resulta interesante que se generen certificados por el término de una relación con otra persona, pero no por no tener una desde un principio. Quizá esto se relacione con el negocio que representa tener un documento que avala que se inició o se terminó una relación con otra persona.

Un tercer antecedente es el artista español David Trullo (2010) con su obra Una historia verdadera. En esta obra, Trullo, interesado en visibilizar lo que ha permanecido oculto, manipuló una serie de imágenes del siglo XIX para crear nuevas en las que muestra parejas del mismo género. El papel la fotografía como registro de la realidad es cuestionado por el artista, quien señala en esta obra aquellas relaciones que nunca fueron representadas. Así, la ficción presentada por Trullo al final podría no serlo tanto y es justamente esta idea que ha sido retomada en Carnet de soltero/a con una proyección temporal diferente. Mientras Trullo imagina viendo hacia el pasado nosotros lo hemos hecho viendo hacia el futuro. Si bien la definición de soltero/a no ha cambiado, cuando lo haga, sin duda, tendrá efectos sobre la población que pertenece a este sector, mientras que en el presente la posibilidad de una actualización nos ha hecho analizar las consecuencias globales de hechos a escala local como lo es una reunión o la publicación de un rumor.

Finalmente, y como un referente adicional, quisiéramos referirnos a The proposal de la artista estadounidense Jill Magid (2016). En 1995, Rolf Fehlbaum, presidente de Vitra, una empresa suiza dedicada al diseño interior y a la creación de muebles, compró el archivo profesional del arquitecto mexicano Luis Barragán (1902-1988) y se lo dio como regalo de compromiso a la actual directora de la Fundación Barragán, Federica Zanco. Desde entonces estos documentos están en un búnker en la sede de la compañía. La pieza de Magid consistió en crear un diamante con 525 gramos de las cenizas de Luis Barragán, montarlo en una argolla y ofrecérselo como anillo de compromiso a Federica Zanco, a cambio de que el archivo del arquitecto sea devuelto a México. Se presentó la propuesta a la familia del arquitecto, quienes estuvieron de acuerdo, luego al gobierno de Guadalajara, quien dio la autorización. El 23 de septiembre de 2015 la artista tomó los 525 gramos de la urna de Luis Barragán y los llevó a Coira, Suiza, donde fueron convertidos en un diamante de 2.02 quilates. El anillo es propiedad de la familia del arquitecto y de la artista y ninguna de las partes puede venderlo. La pieza fue exhibida en la exposición del mismo nombre del 4 de junio al 21 de agosto en la Kunst Halle Sankt Gallen en Suiza. La propuesta fue hecha a Federica Zanco el 31 de mayo de 2016 y Zanco dijo que no. Aunque el anillo de compromiso está presente en las dos piezas, en la de Lambert y en la de Madig, resulta interesante ver cómo sus perspectivas difieren. Para la primera la obligación no tiene que estar asociada necesariamente a un objeto ni a un documento, mientras que para la segunda dicha asociación es fundamental, además de que entiende primordialmente al anillo de compromiso como un instrumento de negociación. También se debe destacar The proposal como una pieza con un perfil global al intentar llegar a un acuerdo en el que está involucrado el intercambio de documentos y objetos entre organizaciones pertenecientes a dos países diferentes.

Carnet de soltero/a se desarrolló con el objetivo de favorecer una reflexión sobre las consecuencias de que los/las solteros/as fueran definidos en términos de discapacidad y retomando de los referentes mencionados el ofrecer un beneficio al ciudadano (de Mejor Vida Corp.), el generar un documento gratuito que avale que los solteros/as no tienen una relación (de Wedding Project), el imaginar situaciones ficticias que son realmente posibilidades (de Una historia verdadera) y el realizar un intercambio en el que los participantes obtienen un carnet que les ofrece ventajas virtuales a cambio de proporcionar información personal (de The proposal). La pieza consistió en emitir identificaciones para personas mayores de edad, que no tuvieran hijos y cuyo estado civil fuera ser solteros/as. Aunque en realidad los carnets no fueron avalados por ningún órgano de gobierno, sus rasgos esenciales se copiaron de las identificaciones emitidas por el INGUDIS (Instituto Guanajuatense de la Discapacidad). Como se puede observar en la ilustración 2 , en el frente de cada carnet aparece esta información: el nombre del país (Estados Unidos Mexicanos) y su escudo; el nombre de la institución que los emite (Sistema Nacional para el Desarrollo Integral de la Familia, cuyas siglas, DIF, aparecen también en marca de agua); el nombre del carnet (credencial nacional para personas con discapacidad); folio; nombre, dirección, registro federal de contribuyentes (RFC), fotografía y firma de la persona; tipo de discapacidad (soltero/a); y el nombre y firma del funcionario (del artista). En el reverso se indica el nombre, dirección y número telefónico de una persona con quien comunicarse en caso de emergencia; la huella digital de la persona con discapacidad; la leyenda "Esta credencial es personal e intransferible"; y un código de barras. 
Carnet de soltero/a: un proyecto artístico guanajuatense con referentes globales

III CONGRESO INTERNACIONAL DE INVESTIGACIÓN EN ARTES VISUALES :: ANIAV 2017 :: GLOCAL [codificar, mediar, transformar, vivir] http://dx.doi.org/10.4995/ANIAV.2017.4821
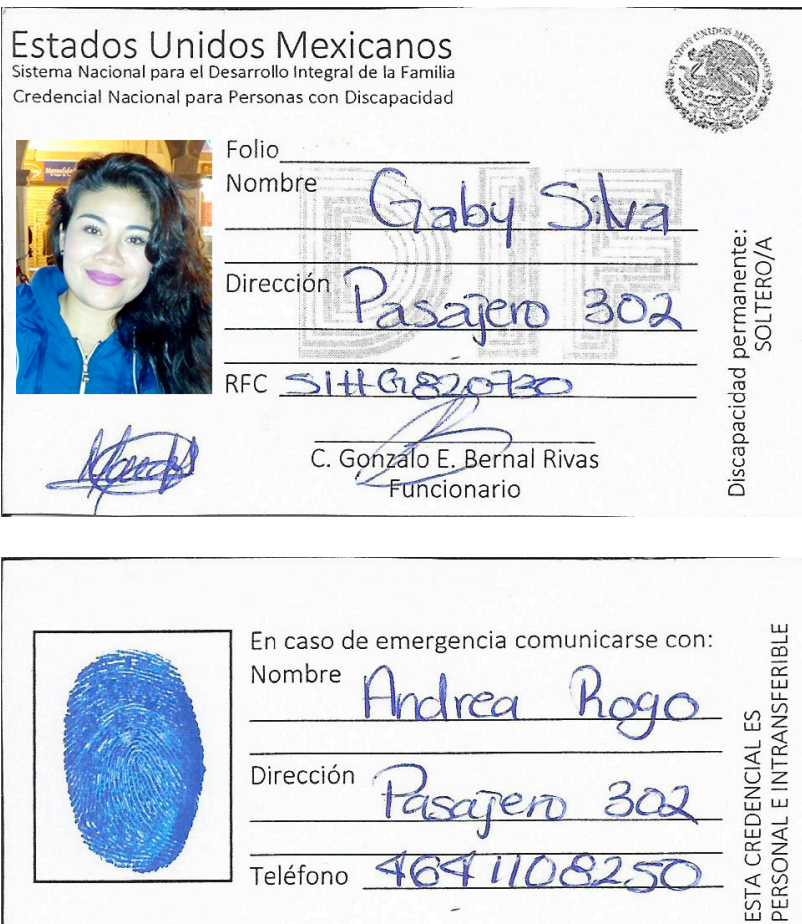

|||||||||||||||||||||||||||||||||||||||||||||||||||||||||||||||||||||||||||||||||||||||

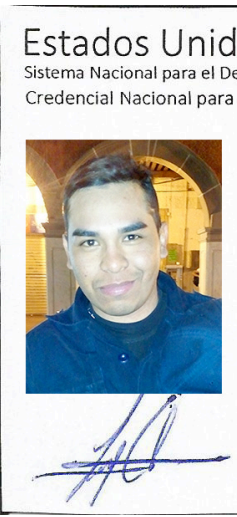

idos Mexicanos
l Desarrollo Integral de la Familia

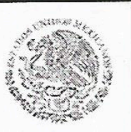

Folio
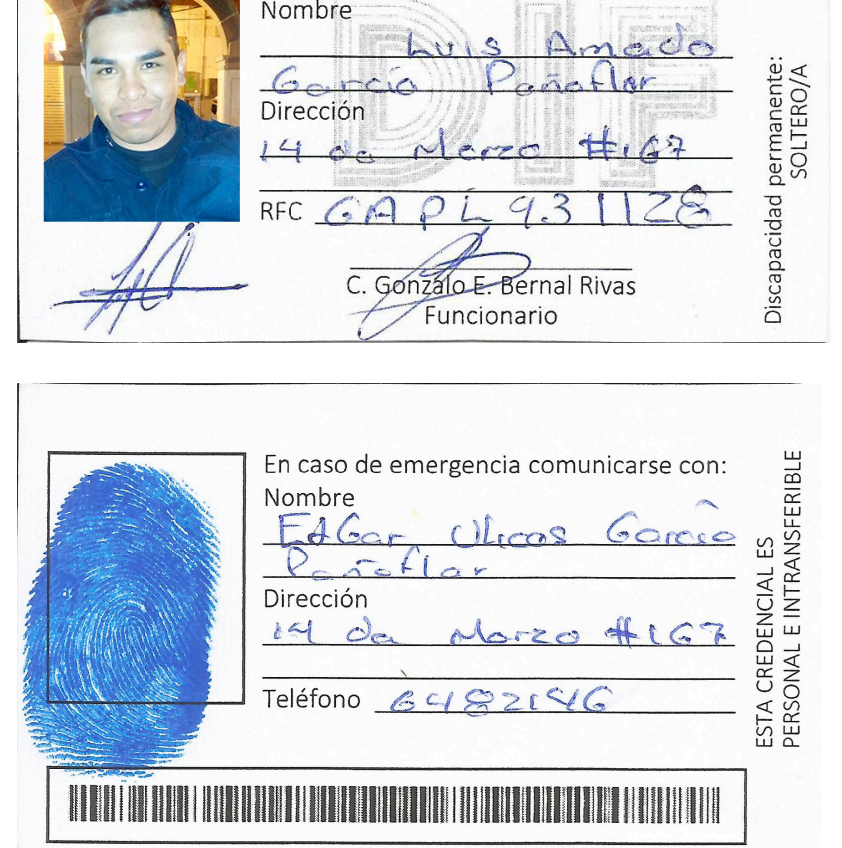
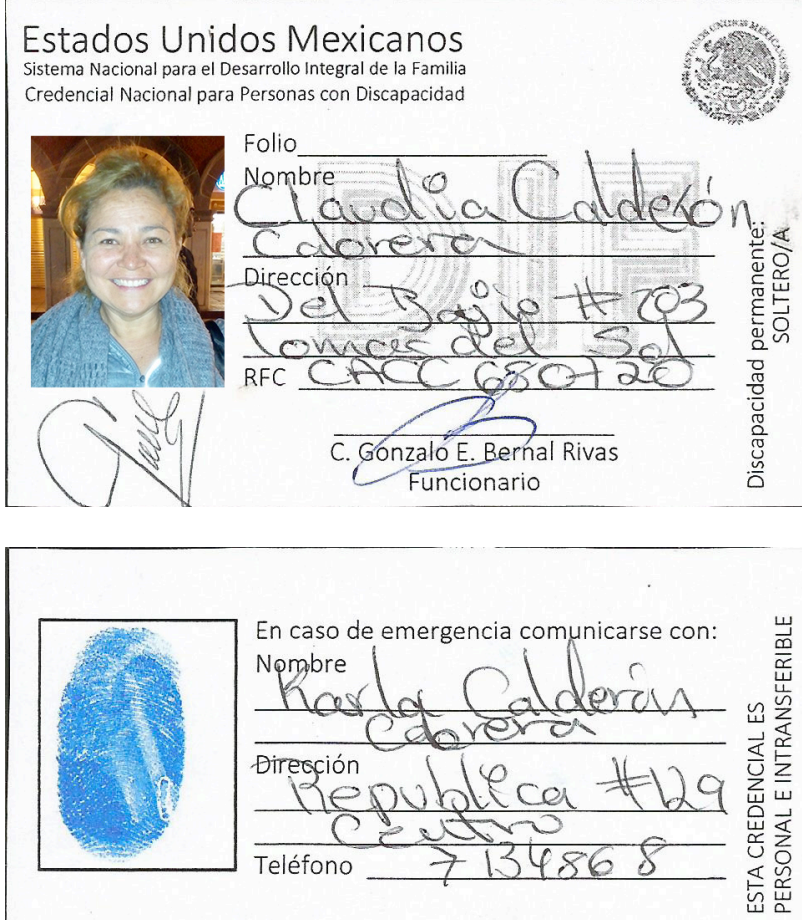

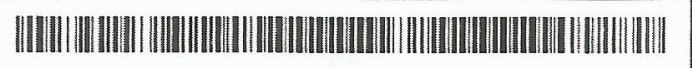
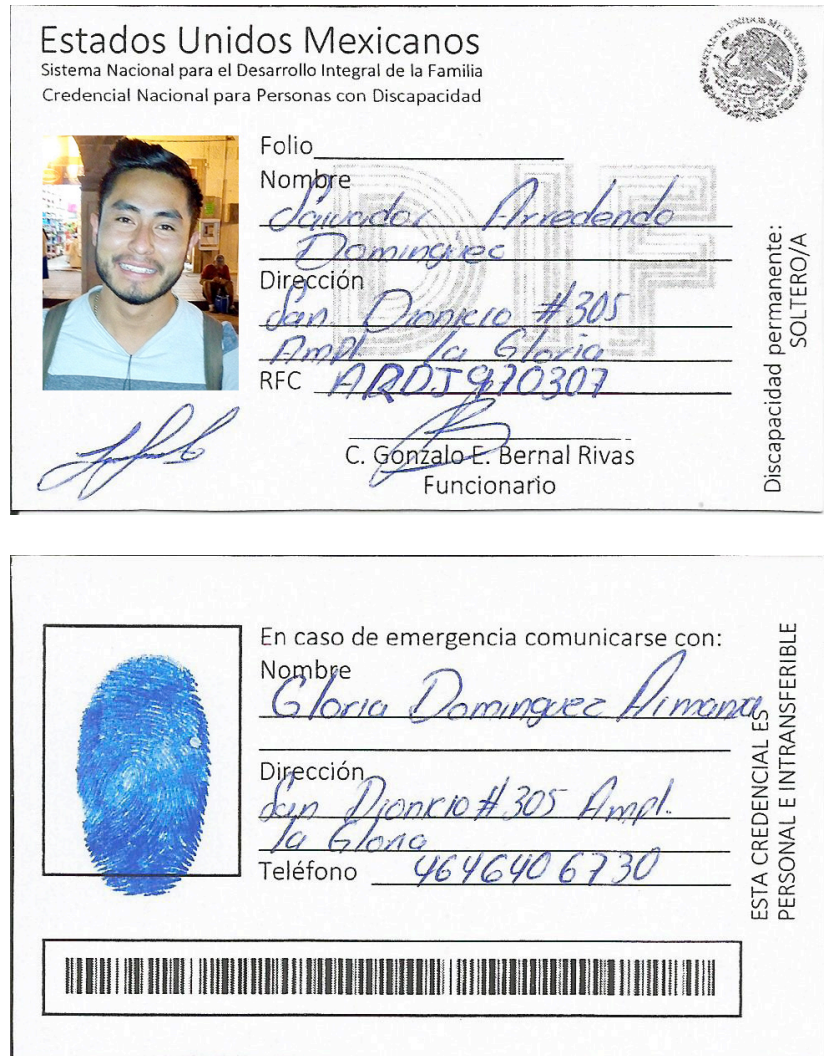

Ilustración 1. Cuatro de los carnets emitidos. 
Los carnets se ofrecieron en la plaza principal de la ciudad de Salamanca, Guanajuato, el 10 de febrero de 2017 entre las 17 y las 21 hrs. Se emitió un total de 15 carnets, los cuales se digitalizaron y entregaron en el momento en el que fueron solicitados. También se hizo entrega a los participantes de la ficha informativa que se muestra en la ilustración 3.

"La presencia de experiencias espaciales en el arte moderno mexicano y su influencia sobre el arte de la experiencia del espacio humano creado en México y en el extranjero en el siglo XXI."

Proyecto de investigación artística

\section{FICHA INFORMATIVA}

Nombre de esta pieza: Credencial de soltero INGUDIS (Instituto Guanajuatense para personas con discapacidad)

Descripción

La pieza consiste en la emisión de credenciales de soltero/a que avalan a sus poseedores/as como discapacitados/as.

\section{Antecedentes}

El 20 de octubre de 2016, el periódico The telegraph publicó una nota de Henry Bodkin en el que reveló que la OMS (Organización Mundial de la Salud) definiría como "infértiles" a las personas solteras, y por lo tanto, de acuerdo al glosario de la misma organización, como "discapacitadas". En este texto escribió:

"La organización Mundial de la Salud está por anunciar que los hombres y mujeres sin problemas médicos serán clasificados como infértiles si no tienen hijos, pero quieren volverse padres."|

http://www.telegraph.co.uk/news/2016/10/19/single-men-will-get-the-right-to-start-a-family-undernew-defini/

El 21 de octubre de 2016 la OMS declaró:

“La OMS está colaborando actualmente con sus compañeros para actualizar el Glosario y se está considerando revisar la definición de infertilidad. De haber un cambio en la definición de infertilidad, esta se mantendrá como una descripción clínica de infertilidad como una enfermedad del sistema reproductivo y no se harán recomendaciones sobre disposiciones de los servicios de cuidado de la fertilidad."

http://www.who.int/reproductivehealth/topics/infertility/multiple-definitions/en/

$\mathrm{Si}$ los/as solteros/as fuéramos considerados/as como discapacitados/as ¿tendríamos beneficios? ¿podríamos tener una credencial que nos identificara como tales? ¿tendríamos placas que nos permitirían ubicar nuestros vehículos en cajones de estacionamiento exclusivos? ¿podríamos usar los asientos preferentes en los teatros o en el transporte público? ¿o podríamos formarnos en las filas preferentes en los bancos?

\section{Objetivo General}

Favorecer una reflexión sobre las experiencias de injusticia del espacio humano que vivimos diariamente a través de la concepción y construcción de una serie de vivencias espaciales ficticias o reales.

\section{Objetivo Particular}

Motivar la generación de pensamiento crítico sobre las vivencias de injusticia espacial vinculadas con el estado civil que un hecho como el descrito generaría.

Riesgos a que se sujetan los participantes: En el corto plazo, en la pieza Credencial de soltero INGUDIS existe el riesgo de violencia, verbal, psicológica o física.

Beneficios que se pueden obtener del análisis que se propone: El individuo y la comunidad podrían resultar beneficiados de una reflexión sobre las experiencias de injusticia del espacio humano que vivimos diariamente.

Duración de la intervención: 10 de febrero de 2017

Suspensión del estudio: Bajo la detección de cualquier muestra de violencia la pieza será suspendida. Libertad de los participantes: Los asistentes pueden retirarse libremente en cualquier momento que lo deseen

Gracias por tu participación

\section{Ilustración 3. Ficha técnica de Carnet de soltero/a.}


Por otra parte, como se puede apreciar en la ilustración 4, algunos de los recursos materiales empleados fueron: las fichas informativas y los carnets previamente impresos; una mesa y una silla; una extensión; un ordenador portátil y una impresora; bolígrafos, pegamento, tijeras y un cojín con tinta azul. Finalmente, es oportuno mencionar un par de retos que fue necesario superar durante el desarrollo de la pieza. La primera de ellas fue la negociación para conseguir alimentación eléctrica para la impresora. Previo al desarrollo de la pieza se consiguió el apoyo de una vendedora que nos permitiría conectar la impresora a su kiosco, sin embargo, el día de la ejecución esta persona no estaba en el espacio público, lo cual nos obligó a conseguir ayuda de alguien más. Un bolero nos permitió usar la electricidad de su caseta a cambio de pagarle el equivalente a cinco euros. Un segundo desafío fue el riesgo a ser detenidos al que nos expusimos al emitir identificaciones apócrifas. Durante la realización de la pieza un grupo de policías se aproximó y preguntó por los carnets. Al contrario de lo que esperábamos, uno de ellos solicitó su identificación, la cual puede encontrarse en la ilustración 3.

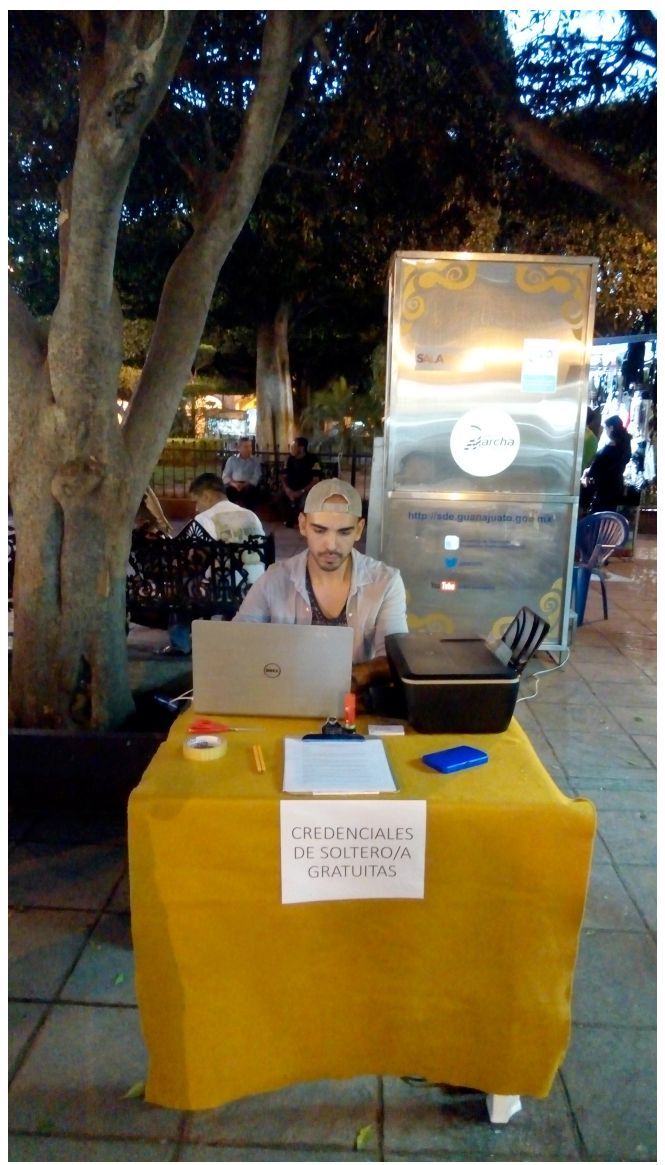

llustración 4. Emisión de carnets de soltero/a.

\section{Conclusiones}

Partiendo de una serie de antecedentes teóricos, históricos y artísticos se creó una obra de arte de la experiencia del espacio humano que favoreció una reflexión entre los participantes: señalar a los/las solteros/as sería una medida de segregación más que una protección y definirlos/as en términos de discapacidad les otorgaría beneficios innecesarios, entre los cuales destacaría la obtención de un carnet.

Por otra parte, la pieza contribuyó a la generación de un análisis sobre el rol de los medios de comunicación en un mundo globalizado y también ayudó a repensar el impacto universal que puede tener la decisión tomada por un pequeño grupo de personas. Por el contrario, nos permitió analizar la influencia global que recibimos como artistas locales derivado del uso del internet y de los viajes internacionales principalmente, así como considerar la huella ambiental que estas actividades implican. 


\section{FUENTES REFERENCIALES.}

ANAUT, Alberto. Arte español contemporáneo 1992-2013. Madrid: La fábrica, 2013.

BERNAL, Gonzalo. Cuestionamiento y recuperación de la experiencia del espacio humano en el arte mexicano contemporáneo (19972014). Valencia: Universidad Politécnica de Valencia, 2015.

CULLEN, Deborah. Arte=vida: actions by artists of the Americas, 1960-2000. Nueva York: Amerikon Group, 2008.

GILLICK, Liam y LIND, Maria. Curating with light luggage: reflections, discussions and revisions. Berlín: Ed. Revolver, 2005.

BOURRIAUD, Nicolas. Estética relacional. Buenos Aires: Adriana Hidalgo Editora, 2006.

GROYS, Boris et all. The art of participation. 1950 to now. San Francisco: Thames and Hudson, 2008.

http://www.revistacodigo.com/luis-barragan-convertido-en-anillo-entrevista-con-jill-magid/

http://www.telegraph.co.uk/news/2016/10/19/single-men-will-get-the-right-to-start-a-family-under-new-defini/

https://www.vitra.com/es-Ip/home

http://www.who.int/

RAMÍREZ, María Isabel. El espacio urbano y arquitectónico como espacio del hombre. La conquista del lugar. Thémata, no. 11, 1993, 126-133.

SOJA, Edward W. En busca de la justicia espacial. Valencia: Tirant humanidades, 2014. 